\title{
Canadian Engineers Missing Lean Thinking
}

\author{
Chris Mackie, P. Eng. \\ Manufacturing / Systems Engineer \\ Westeel Limited \\ mackie2@mts.net
}

\begin{abstract}
Lean thinking has become a part of North American manufacturing and service sectors. This is occurring in an atmosphere of growing customer demands, heavier reliance upon technology and new environmental challenges. The move to create more agile and responsive organizations has become a global race to perfection and of survival. An ever-expanding list of industries and areas of the economy are moving to become lean. Canadian engineers of many disciplines are being called upon to rise to this challenge, yet most do not receive anything more than a brief introduction to lean through their undergraduate studies.
\end{abstract}

What is lean thinking? Lean is simply eliminating all waste within any process. Waste is anything your customer does not wish to pay for. There are 8 different forms of waste. They are: overproduction, inventory, waiting, transportation of materials, motion, inefficient processes, rework and not using your people's abilities to the fullest.

Leaning an organization is through reducing the lead time between the customer's request and fulfilling that request. Value added steps are retained and non-value added steps are removed to reduce cost and time requirements.

The paradigm has changed for design and consulting engineers. For example, system and machine designs that do not continue to reduce or eliminate the costs associated with not only operation and maintenance but now also setups will undermine the success of those engineers and their firms. This is because lean focuses on the waste of setups within processes. Additional tools such as design for manufacturing (DFM), design for assembly (DFA), design for operations (DFO) and quality functional deployment (QFD) are critical skills in the new paradigm.
Developing an organizational culture where individual leadership is widespread, spontaneous and visibly supported is a fundamental lean skill. Entire firms are trained in problem solving skills. All of these efforts, through a consistent method, are to create an enterprise-wide continuous improvement culture.

Lean knowledge and the ability to pass it on to others are the fundamental skills that Canadian engineers need to be successful.

Some Canadian engineers may fall further behind in this race to become lean. The gap will continue to widen between an ever-growing need for lean education and Canada's ability to fill it. Canadian universities must respond to this need in an effort to create well-rounded engineers and to sustain the Canadian economy and standard of living.

\section{Introduction}

What is lean thinking? Lean is simply the elimination of waste in every aspect of an organization's operation while improving the value of the product and/or service. [1] Value is whatever your customer is willing to pay for. Conversely, waste is anything your customer does not wish to pay for.

There are 8 forms of waste:

1. The first form of waste is overproduction, which is producing more than is needed or producing the correct amount too early. This first form of waste is usually the most detrimental since extra production leads to many of the following wastes.

2. Inventory waste is tying up capital in the form of raw materials and warehousing costs.

3. Another waste is waiting; waiting for tools, materials, information, etc. 
4. The waste of transportation also does not pass the lean "litmus test". Transportation of a resource does not change the fit, form or function of the resource being moved. Therefore, this action is pure waste.

5. The waste of motion is any unnecessary movement of the staff to complete a task. Common examples include poor ergonomics in an operating room or a shop floor workstation and the location of a frequently used fax machine two rooms away in a typical office environment.

6. The waste of inefficient processes deals with systems, procedures and processes that are not the best possible practice. An example is using a hand wrench when a power wrench could do the job in a fraction of the time and effort. Another example is taking the time to collect, key in and report performance metrics where no follow-up or correction action is intended or undertaken.

7. Another form of waste is rework. Having to undo one's task, and redo it clearly consumes more resources than doing the task "right first time".

8. An eighth form of waste is not using your people's abilities to the fullest. The main "doer" of a series of tasks usually has the best insight. Making all staff feel comfortable to not only make improvement suggestions but also to enact them is a huge advantage for any firm. These workers "may find their work more stressful, because a key objective of lean production is to push responsibility far down the organizational ladder." (Womack, Jones and Roos,1990) Clearly then, without this atmosphere or culture, your organization is wasting its' resources in meeting the customer's request.

In thinking lean, it is important to look at your organization from the standpoint of your customer. Why? If you perceive many value added steps within your process but the customers no longer see value in that particular aspect of the product and/or service, then all of the steps leading to that conclusion is waste within your customers' eyes. Many a sacred cow has met its' demise from this new perspective.
Obviously, recognizing value and non-value added steps in a process is not enough.

\section{Lean leads to continuous improvement}

Eliminating waste and enhancing value is the next step. In truly lean organizations, this step never ends. There are always better ways of meeting your customer's need. Improvement continuously occurs by all staff, not just those that support your direct staff. Continuous improvement happens by equipping and allowing the direct staff themselves to make change happen. Managers are there to help prioritize suggestions, ensure all stakeholders have been heard and ensure resources are present to allow successful change. This long term cultural shift is the basis for truly leaning an organization.

Leaning an organization is through reducing the lead time between the customer's request and fulfilling that request. Value added steps are retained and non-value added steps are removed to reduce cost and time requirements.

Developing an organizational culture where individual leadership is widespread, spontaneous and visibly supported is a fundamental lean skill. Entire firms are trained in problem solving skills. All of these efforts, through a consistent method, are to create an enterprise-wide continuous improvement culture.

\section{Why is lean important to university educators and their customers?}

Lean by its' nature can be utilized by many sectors, industries and institutions. Recently a presentation by Daryl Urquhart of Shouldice Hospital, located in Thornhill, Ontario, illustrated how far reaching lean principles can affect their hospital and their customers/patients. It was a remarkable presentation in that those lean principles have been demonstrated in a non-manufacturing environment. However, Shouldice is one of only a few Canadian hospitals that is not falling behind its' American counterparts, where lean health care is widely practiced. Biomedical engineers would do very well to see and learn from the Shouldice example. Several tried and true approaches were removed or significantly altered when lean was applied.

As particular market elements begin to adapt and change to become more lean, it follows that their competition will follow suit or begin to have its' customer foundation erode. For the customer, they 
realize that a market player can offer them a product and/or service, with the same or better quality and safety, in less time for less money. This is what is driving the move to lean worldwide.

\section{Why is lean important to university engineering educators and their customers?}

The paradigm has changed for design and consulting engineers in many fields. For example, system and machine designs that do not continue to reduce or eliminate the costs associated with not only operation and maintenance but now also setups will undermine the success of those engineers and their firms. This is because lean identifies the waste of setups within processes as inefficient or non-value added time.

\section{What needs to be done?}

Clearly, most engineering fields are involved in machine design in some form. By not understanding lean design principles and how to apply them, the companies that make those machines will not succeed for very long as more and more industry purchasing decisions are based upon lean concepts. Additional tools such as design for manufacturing (DFM), design for assembly (DFA), design for operations (DFO) and quality functional deployment (QFD) are critical skills in this new paradigm. Lean product development, procurement and change management skills should be introduced along with the first year team design project, which are found in most Canadian engineering faculties. Certainly these student skills should be honed before the final year capstone design project is assigned. However, this body of lean knowledge, while large in its scope, need not be intrusive to a very full curriculum already.

Additionally, it is predictable that the manufacturing/industrial engineering discipline has the most to gain with early lean understanding. Not only because lean was first embraced by this sector of the economy, but because these staff are most often looked upon as the leaders in implementing lean. These professionals are commonly called lean change agents in most economic sectors.

It is widely suggested by those in the lean community that engineering faculties across our country work together with Canada's best and brightest lean practitioners to develop their programs in this new light. [3] Many core courses need only add lessons on applied lean principles to ensure the undergrad's understanding includes lean.

However, many core courses for manufacturing/industrial engineering, such as system simulation and quality assurance to name two, require much stronger emphasis upon lean as the foundation of their curriculum topics. This is not removing current curriculum; this is providing a new scope of understanding of how the $4 \mathrm{P}$ 's, people, processes, (lean) philosophy and problem solving, work together to reach a common goal. [4]

In addition, this lean knowledge and the ability to pass it on to others are fundamental skills that Canadian engineers need to be successful.

\section{Conclusion}

Some Canadian engineers may fall further behind in this race to become lean. The gap may continue to widen between an ever-growing need for lean understanding and Canada's ability to fill it. Canadian universities must first understand and then respond to this need in an effort to create well-rounded engineers and to sustain the Canadian economy and standard of living.

\section{References}

[1] James J. Womack and Daniel T. Jones, Lean Thinking, Simon and Schuster, New York, 1996

[2] James J. Womack, Daniel T. Jones and Daniel Roos, The Machine That Changed The World, HarperPerennial, New York, 1990

[3] Dave Hogg, Keynote Speaker, 2007 Canadian Lean Conference, personal conversation, 2007

[4] Jeffrey Liker, The Toyota Way, McGraw-Hill, Toronto, 2004 